\title{
Performance Appraisal-A Documentation and Evaluation of Employees
}

\author{
Almas Sabir \\ Department of Management, College of Business Administration, University of Hail, Hail, Kingdom of Saudi Arabia \\ Email address: \\ almas.sabir083@gmail.com \\ To cite this article: \\ Almas Sabir. Performance Appraisal-A Documentation and Evaluation of Employees. American Journal of Management Science and \\ Engineering. Vol. 2, No. 2, 2017, pp. 29-34. doi: 10.11648/j.ajmse.20170202.12
}

Received: April 10, 2017; Accepted: April 24, 2017; Published: June 3, 2017

\begin{abstract}
In this paper, main focus is to highlight certain aspects of performance appraisal in the organization as performance appraisal is an essential part of the human resources to an organization. This paper will also focus on critical needs of evaluating employees in organization. Practical flaws have also been discussed to understand fair and consistent reward Program me.
\end{abstract}

Keywords: Performance, Appraisal, Assessments, Employee Development, Employee Appraisal, Orientation Process

\section{Introduction}

Performance Appraisals is the assessment of individual's performance in a systematic way. It is a developmental tool used for all round development of the employee and the organization. The performance is measured against such factors as job knowledge, quality and quantity of output, initiative, leadership abilities, supervision, dependability, cooperation, judgment, versatility and health. Assessment should be confined to past as well as potential performance also. The second definition is more focused on behaviors as a part of assessment because behaviors do affect job results.

Job performance is a central issue in the psychology of work and occupations. In many ways it has often been argued that the main goal of an occupational psychologist is to improve job performance.

For example, an occupational psychologist conducts a job analysis with a view to defining, as accurately as possible, the best person to perform the job. The primary aim of optimizing the techniques of recruitment and selection is to find the best possible person to fill the vacant post and perform the role in question. Ergonomic design of work settings is conducted in order to optimize the post-holder's comfort and efficiency in performing the role, and thus creating an environment which facilitates the optimum job being completed. In turn, improved job performance results in greater productivity and economic viability. Improvements in job performance are often used as outcome measures in our research: no doubt you will have been more impressed by studies which show how interventions enhance job performance than you might by ones which show employees 'feel better'.

If influencing job performance is central to the role of an occupational psychologist then we must find good ways of measuring it. In essence, we need sensitive, reliable, valid, fair and practical methods of measurement. However, as we will see in this unit, some of the goals of performance appraisal are more dependent upon accurate measures of performance than others.

Performance appraisal is a term applied to a variety of processes that involve the assessment and development of an individual and their performance at work. In the United Kingdom, performance appraisal has been with us for the best part of a century. While it is to a large extent about evaluating a person's performance at work, three key issues are worth bearing in mind:

(1) Performance appraisal is a two-way process. As much as the employer wishes to measure and understand an employee's performance, the employee wishes to gain something from the process.

(2) The appraisal process is about the development of staff as well as about assessing their performance; it is about exploring the appraisee's potential for development in terms of their career;

(3) In appraisal there is an important issue about the extent to which one looks at the overall picture of the individual and what they bring to the workplace 
beyond doing the basic job tasks and activities (e.g. to what extent do they help their team to function more effectively?).

\subsection{Development of Performance Appraisal}

While the term performance appraisal has meaning for most small business owners, it might be helpful to consider the goals of an appraisal system. They are as follows:

(1) To improve the company's productivity.

(2) To make informed personnel decisions regarding promotion, job changes, and termination.

(3) To identify what is required to perform a job (goals and responsibilities of the job).

(4) To assess an employee's performance against these goals.

It is an annual review of an employee's overall contributions to the company by his/her manager. Performance appraisals, also called annual reviews, evaluate an employee's skills, achievements and growth, or lack thereof.

\subsection{It Is Said That Performance Appraisal Is an Investment for the Company Which Can Be Justified by Following Advantages}

(1) Promotion: Performance Appraisal helps the supervisors to chalk out the promotion programmes for efficient employees. In this regards, inefficient workers can be dismissed or demoted in case.

(2) Compensation: Performance Appraisal helps in chalking out compensation packages for employees. Merit rating is possible through performance appraisal. Performance Appraisal tries to give worth to a performance. Compensation packages which include bonus, high salary rates, extra benefits, allowances and pre-requisites are dependent on performance appraisal. The criteria should be merit rather than seniority.

(3) Employees Development: The systematic procedure of performance appraisal helps the supervisors to frame training policies and programmes. It helps to analyze strengths and weaknesses of employees so that new jobs can be designed for efficient employees. It also helps in framing future development programmes.

(4) Selection Validation: Performance Appraisal helps the supervisors to understand the validity and importance of the selection procedure. The supervisors come to know the validity and thereby the strengths and weaknesses of selection procedure. Future changes in selection methods can be made in this regard.

(5) Communication: For an organization, effective communication between employees and employers is very important. Through performance appraisal, communication can be sought for in the following ways:

a Through performance appraisal, the employers can understand and accept skills of subordinates.

b The subordinates can also understand and create a trust and confidence in superiors.

c It also helps in maintaining cordial and congenial labor management relationship.

d It develops the spirit of work and boosts the morale of employees.

All the above factors ensure effective communication.

(6) Motivation: Performance appraisal serves as a motivation tool. Through evaluating performance of employees, a person's efficiency can be determined if the targets are achieved. This very well motivates a person for better job and helps him to improve his performance in the future.

\subsection{Planning for Performance}

Setting Expectations and Goals

Understanding the mission and goals of the University and your organization provides a context in which to develop performance standards and goals. It gives you a framework and a direction. Of primary importance, is the employee's ability to see how their performance expectations and goals are linked to the mission of the department?

Setting Expectations what is a Performance Expectation?

(1) A description of the results expected for the fully satisfied performance of a job function/task.

(2) Defines "how well" each function or task must be performed.

(3) Provides a benchmark against which to evaluate work performance.

When Should Performance Expectations be Set?

(1) When an employee is hired

(2) When responsibilities are changed or added

(3) When clarification of responsibilities is needed

A performance expectation should be:

(1) Derived from mission, goals and values

(2) Mutually understood

(3) Developed collaboratively, if appropriate

(4) Descriptive of how a job is to be performed

(5) Descriptive of fully satisfactory performance

(6) Expressed in measurable/observable terms

(7) Reasonable and attainable

\section{Methods/Techniques of Performance Appraisals}

Numerous methods have been devised to measure the quantity and quality of performance appraisals. Each of the methods is effective for some purposes for some organizations only. None should be dismissed or accepted as appropriate except as they relate to the particular needs of the organization or an employee.

Broadly all methods of appraisals can be divided into two different categories.

(1) Past Oriented Methods

(2) Future Oriented Methods

Past Oriented Methods

(1) Rating Scales: Rating scales consists of several 
numerical scales representing job related performance criterions such as dependability, initiative, output, attendance, attitude etc. Each scales ranges from excellent to poor. The total numerical scores are computed and final conclusions are derived.

(2) Checklist: Under this method, checklist of statements of traits of employee in the form of Yes or No based questions is prepared. Here the rater only does the reporting or checking and $\mathrm{HR}$ department does the actual evaluation.

(3) Forced Choice Method: The series of statements arranged in the blocks of two or more are given and the rater indicates which statement is true or false. The rater is forced to make a choice. HR department does actual assessment.

(4) Comparative Evaluation Method (Ranking \& Paired Comparisons): These are collection of different methods that compare performance with that of other co-workers. The usual techniques used may be ranking methods and paired comparison method.

a Ranking Methods: Superior ranks his worker based on merit, from best to worst. However how best and why best are not elaborated in this method. It is easy to administer and explanation.

b Paired Comparison Methods: In this method each employee is rated with another employee in the form of pairs. The number of comparisons may be calculated with the help of a formula as under.

(5) Essay Method: In this method the rater writes down the employee description in detail within a number of broad categories like, overall impression of performance, promote ability of employee, existing capabilities and qualifications of performing jobs, strengths and weaknesses and training needs of the employee.

Future Oriented Methods

1. Management by Objectives: It means management by objectives and the performance is rated against the achievement of objectives stated by the management. MBO process goes as under.

Establish goals and desired outcomes for each subordinate

(1) Setting performance standards

(2) Comparison of actual goals with goals attained by the employee

(3) Establish new goals and new strategies for goals not achieved in previous year.

2. Psychological Appraisals: These appraisals are more directed to assess employees' potential for future performance rather than the past one. It is done in the form of in-depth interviews, psychological tests, and discussion with supervisors and review of other evaluations. It is more focused on employees emotional, intellectual, and motivational and other personal characteristics affecting his performance. This approach is slow and costly and may be useful for bright young members who may have considerable potential. However quality of these appraisals largely depends upon the skills of psychologists who perform the evaluation.

3. 360-Degree Feedback: It is a technique which is systematic collection of performance data on an individual group, derived from a number of stakeholders like immediate supervisors, team members, customers, peers and self. In fact anyone who has useful information on how an employee does a job may be one of the appraisers.

\section{Result}

\subsection{After Analyzing Performance Appraisal Methods Following Are the Result to Make It Easy}

(1) Performance appraisals are essential for the effective management and evaluation of staff.

(2) Appraisals help to develop individuals, improve organizational performance, and feed into business planning.

(3) Formal performance appraisals are generally conducted annually for all staff in the organization.

(4) Each staff member is appraised by their line manager. Directors are appraised by the CEO, who is appraised by the chairman or company owners, depending on the size and structure of the organization.

(5) Annual performance appraisals enable management and monitoring of standards, agreeing expectations and objectives, and delegation of responsibilities and tasks. Staff performance appraisals also establish individual training needs and enable organizational training needs analysis and planning.

(6) Performance appraisals also typically feed into organizational annual pay and grading reviews, which commonly also coincide with the business planning for the next trading year.

(7) Performance appraisals generally review each individual's performance against objectives and standards for the trading year, agreed at the previous appraisal meeting.

(8) Performance appraisals are also essential for career and succession planning - for individuals, crucial jobs, and for the organization as a whole.

(9) Performance appraisals are important for staff motivation, attitude and behavior development, communicating and aligning individual and organizational aims, and fostering positive relationships between management and staff.

(10) Performance appraisals provide a formal, recorded, regular review of an individual's performance, and a plan for future development.

(11) Job performance appraisals - in whatever form they take - are therefore vital for managing the performance of people and organizations.

(12) Managers appraise commonly dislike appraisals and try to avoid them. To these people the appraisal is daunting and time-consuming. The process is seen as a difficult administrative chore and emotionally challenging. 
(13) The annual appraisal is maybe the only time since last year that the two people have sat down together for a meaningful one-to-one discussion. No wonder then that appraisals are stressful - which then defeats the whole purpose. There lies the main problem - and the remedy.

\section{Discussion on Staff Performance Appraisal Policies, Procedures, \& Forms}

A variety of templates are available for use for the Staff Performance Appraisal process, an annual process required by Policy E27.0 - Staff Performance Appraisal. Supervisors may edit the templates to create a customized set or sets of appraisal forms to evaluate performance and communicate in styles and formats that best fit the types of positions held by the individuals in their respective department(s).

Regardless of the template/format chosen, each performance appraisal must include the following:

(1) An assessment of the employee's commitment to diversity \& inclusion.

(2) A final overall performance rating for the year (using the standard rating scale and definitions). The final rating is an important element of this process as this information will be used to differentiate merit increases in the salary review process and to ensure equity within the two processes.

(3) Signatures from the employee, the supervisor who wrote the appraisal and the manager of that supervisor.

\subsection{Employee Development Plan}

A performance-based employee development plan uses the annual performance appraisal to review previous accomplishments, capabilities and establish goals for the next year. These goals can be solely work-related such as increasing productivity, or the goals could be designed to improve the employee \& rsquo; s skills or education.

For example, when a department manager instructs her employee to complete two continuing education classes in the next 12 months that is a goal that can improve the employee \& rsquo; s skills to prepare him for future roles within the company. Another way to construct a goal from the annual performance plan is to build upon the skills the employee already has to challenge him for the next step in his career.

Remember that development may be addressed in a number of ways, including:

(1) Training (classroom, webinar, seminar, university courses, etc.)

(2) Observation of a skill (job shadowing)

(3) Placement on a project team

(4) On-the-job experience (broadening within a current role)

(5) Independent reading
Table 1. Performance Appraisal Form.

\begin{tabular}{l} 
To: \\
Length of Employee Service in Position: \\
Appraisal Period: From: \\
Empl ID: \\
Name: \\
Job Title: \\
College: \\
Div/Dept: \\
\hline
\end{tabular}

\subsection{Performance Review Tips}

The following tips are applicable in daily conversations with employees. They are also critical in periodic, formal meetings with employees to discuss job goals and performance. These ten tips will help to make performance reviews positive and motivational. They will improve-not deflate - the ability to interact with your reporting employees.

(1) The employee should never hear about positive performance or performance in need of improvement for the first time.

(2) No matter the components of your performance review process, the first step is goal setting.

(3) During preparation and goal setting, you need to make how you will evaluate the employee's performance clear.

(4) If your company uses a form that you fill out in advance of the meeting, give the performance review to the employee in advance of the meeting.

(5) Conversation is the key word that should define a performance review meeting.

\subsection{The Performance Appraisal Process}

In the diagram below you can see that the appraisal process is not an annual event it is a never-ending process, there is no start and no end. it's an ongoing cycle of planning and evaluation of employee performance.

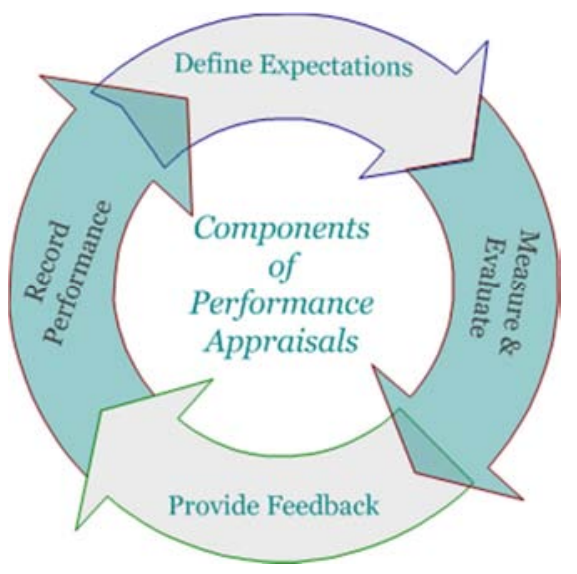

Figure 1. Performance Appraisal Process.

\subsection{Job Evaluation}

Step 1 - Evaluating Performance Appraisal You need to allocate frequent slots within your monthly work schedule 
where you collate and record performance data. An effective way to collect the required data is to ask your team to structure their monthly progress reports in a way that maps to their personal goals.

Step 2 - Appraisal Data Collection You should collect data based on: progress towards goals, third party feedback, and observed competencies, as well as generic data like attendance.

Step 3 - Evaluating Competencies To gain a true appreciation of how well someone is performing and contributing to the organization, you need to gather data about the individual's relationship with third parties. Performance is not solely about attaining targets; how they are achieved also matters.

Step 4 - Performance Appraisal Rating Bias Industrial psychologists have identified ten common causes of bias that affect managers when appraising their team. As you read through this list ask yourself if you have a tendency to act in this way. If you answer 'Yes' then you need to make a conscious effort to avoid the behavior.

Step 5 - Performance Appraisal Rating Scales Most organizations use a 3, 4, 5 or 7-point scale with the most common being a 5-point scale. You will need to communicate to your team members how the 'midpoint' of the scale is defined, so that their expectations are clearly set.

Step 6 - Performance Appraisal Reviews Regular scheduled performance reviews give you the opportunity to identify potential problems before they become serious. These reviews also strengthen the working relationship you have with each member of your team.

Step 7 - Writing an Annual Performance Summary The primary purpose of the annual performance summary is to give the team member constructive feedback on how well they have performed over the period. Ideally, a performance summary should consist of four sections covering goals, competencies, overall performance, and areas of improvement indicating potential training needs.

\section{Conclusion}

Although the specific types of performance appraisals conducted and forms used vary among organizations, these one-on-one meetings help employees understand exactly how they're doing and set goals for development or improvement. Whether the employee you're meeting with has made excellent progress or is struggling to keep up, it's essential to cover key points as to conclude the discussion.

\subsection{Focus on the Positive}

(1) Ending on a positive note helps encourage and motivate employees.

(2) New supervisors sometimes fall into the trap of dwelling on the negatives, but emphasizing an employee's strongpoint's is a more respectful -- and ultimately more effective -- way to close the meeting.

(3) Summarize the areas in which the employee has excelled, either individually or on a team, and express your sincere appreciation for a job well done. Even if his performance has been poor overall, find at least one positive thing to say, for example, "You've clearly been trying very hard to meet your quota," even if he hasn't yet succeeded.

\subsection{Set Clear Goals}

(1) Based on earlier discussions, outline an action plan for the next three months, six months or year, depending on your organization's review schedule and your employee's specific situation.

(2) For instance, struggling employees will need a followup meeting sooner than others.

(3) The action plan typically is outlined on a Human Resources-provided form designed for this purpose as a key part of the appraisal. With your employee's input, compile a list of realistic, measurable goals and a deadline for each.

(4) These may include specific work-related tasks, as well as professional development goals. Be sure to include any areas requiring improvement.

(5) Where Do Managers Go Wrong With Performance Appraisals?

(6) How Can a Manager Successfully Approach Performance Appraisal Goals?

(7) Why Are Performance Reviews Not an Adequate Reflection of Performance.

\subsection{Explain Possible Repercussions}

In most cases, the end of meeting should remain entirely positive. However, if an employee's performance has been mostly inadequate, it may be necessary to explain what will happen if he doesn't improve. Refer to the specific problemrelated goals and dates listed in your action plan, for example, "Failure to make at least 30 sales within three months will result in possible disciplinary actions, up to and including termination." Both before and after conveying this type of warning, express that you are confident he can make the necessary improvements and will do everything possible to help.

\subsection{Wrap It up}

(1) As to conclude the meeting, confirm that the employee understands what is expected of him.

(2) Ask if he has any questions regarding the action plan or any other part of the review, and provide answers that continue to focus on the positive.

(3) Then have him sign the action plan and any other appraisal-related forms. Express that you are committed to helping him succeeds, and encourage him to ask for guidance whenever needed.

\section{References}

[1] http://www.businessballs.com/performanceappraisals.htm. 
[2] https://www.rit.edu/fa/humanresources/content/staffperformance-appraisal-policies-procedures-andforms\#Employee_Development_Plan.

[3] https://corehr.wordpress.com/performancemanagement/performance-appraisal-methods/.

[4] http://www.managementstudyguide.com/performanceappraisal.htm.

[5] https://www.linkedin.com/pulse/20141030184448208256548-hrm-performance-appraisal-methods.

[6] https://www.thebalance.com/effective-performance-reviewtips-1918842.

[7] smallbusiness.chron.com/examples-employee-developmentplan-1906.html.

[8] http://www.whatmakesagoodleader.com/PerformanceAppraisal.html.
[9] https://www.le.ac.uk/oerresources/psychology/individualsatwo rk/unit5/page_02.ht.

[10] Supervisor's Guide to Performance Appraisals June 2015, page- 3,4 .

[11] Evaluating Performance ISBN 978-1-62620-991-6 (35 Pages), Paul Neuton \& Helen Bristol.

\section{Biography}

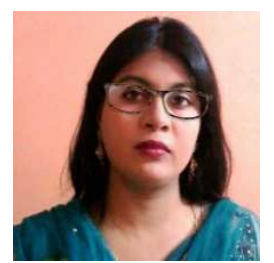

Dr. Almas Sabir earned her Ph. D. degree in Management from Himalayan University, India. She is a lecturer of management in University of Hail, KSA.

She has authored over 10 publications including rewards and recognition, quality assurance, human resource development, operations management. 